\title{
Chklóvski e Tolstói: uma moral do estranhamento
}

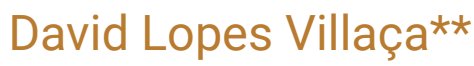

Resumo: Ao utilizar em "A arte como procedimento" alguns trechos de Tolstói como exemplo do que definiu como processo de "estranhamento", Viktor Chklóvski deu-nos uma chave importante para a compreensão da obra do autor. Mas embora tenha tentado explicar a função geral do estranhamento na literatura, não especificou qual o seu papel em Tolstói. Neste trabalho, refletirei sobre alguns aspectos e passagens da obra do autor, buscando compreender as funções do que nela Chklóvski identificou como "estranhamento", à luz das considerações mais amplas que o crítico desenvolveu em seus ensaios.

\begin{abstract}
When in his essay "Art as Procedure" Viktor Chklovski used some excerpts from Tolstoy as an example of what he defined as a process of "estrangement", he gave us an important key to understand his work. However, while he tried to explain the function of estrangement in literature, he did specify its role in Tolstoy. In this paper, I will reflect on some aspects and passages of the author's work, seeking to understand the functions of what Chklovski identified in it as estrangement, in light of the broader considerations that the critic has developed in his essays.
\end{abstract}

Palavras-chave: Tolstói; Chklóvski; Estranhamento.

Keywords: Tolstoy; Shklovsky; Estrangement. 
*Artigo submetido em 20 de setembro de 2019 e aprovado em 06 de outubro de 2019.

**Aluno de doutorado do departamento de Teoria Literária e Literatura Comparada da Faculdade de Filosofia, Letras e Ciências Humanas da Universidade de São Paulo. E-mail: dlvillaca@uol.com.

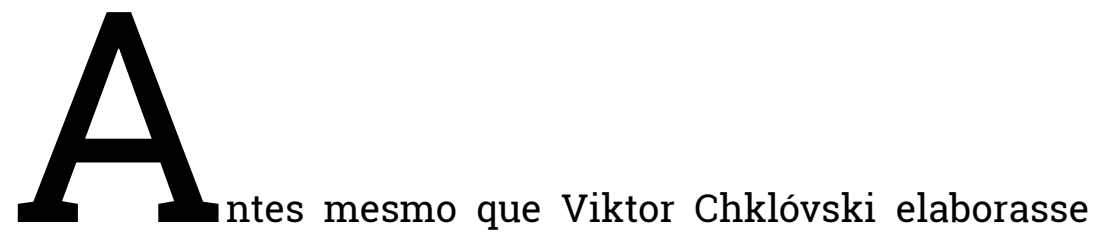
seu conceito de estranhamento cunhado em "A arte como procedimento", suas bases já estavam dadas em "A ressureição da palavra". Neste ensaio, o crítico pensava sobretudo na relação da poesia com a palavra:

The most ancient human poetic creation was the creation of words. Today words are dead, and language resembles a graveyard, but new-born words were alive and vivid. [...]. And often, when you get through to the lost, effaced image wich was the original source of the word, you find yourself struck by its beauty - the beauty witch existed once, and is no more.

When words are used as general concepts, when they serve, so to speak, as algebraic symbols devoid of imagery, when they are used in everyday speech, when they are neither fully spoken nor fully heard - then they become familiar, and neither their internal forms (images), nor the internal one (sounds) are experienced anymore. We do not experience the familiar; we do not see but only recognize it. We do not see the walls of our rooms, we find it hard to spot a misprint in a proof, particularly in a familiar language - because we cannot make ourselves see, read a familiar word instead of "recognizing" it. ${ }^{1}$

Para Chklóvski, a poesia, ou mais genericamente as artes, têm como objetivo voltar a nos fazer experienciar as formas deste mundo, vê-las, ao invés de meramente reconhecê-las. Tudo o que se reconhece, tudo o que se tornou usual foi submetido, na visão do crítico, a uma automação da percepção e já não é propriamente nem visto nem sentido.

Tal como a palavra foi a primeira criação poética do homem, o próprio mundo nalgum momento teria constituído uma manifestação poética para toda a humanidade. É o que se pode deduzir das seguintes observações de Chklóvski:

1 CHKLÓVSKI, 2016, p. 63-64. 
Nowadays, old art has already died, new art has not yet been born, and things have died. We have lost our awareness of the world; we resemble a violinist who has ceased to feel the bow and strings; we have ceased being artists in everyday life, we do not love our houses and our clothes, and we easily part with life, for we do not feel life. Only the creation of new arts forms can restore man the experience of the world, can resurrect things and kill pessimism. ${ }^{2}$

Essa noção a respeito de uma antiga experiência poética do mundo (que Chklóvski, então com pouco mais de vinte anos, parece desenvolver de forma bastante intuitiva) adequa-se muito bem às considerações posteriores de Mircea Eliade acerca da relação do homem primitivo com os mitos, que subsistiria de algum modo na relação do homem moderno com a literatura. Diz o mitólogo, no final de Mito e realidade, empregando termos que fazem inclusive lembrar Chklóvski:

De modo ainda mais intenso que nas outras artes, sentimos na literatura uma revolta contra o tempo histórico, o desejo de atingir outros ritmos temporais além daquele em que somos obrigados a viver e a trabalhar. Perguntamo-nos se esse anseio de transcender o nosso próprio tempo, pessoal e histórico, e de mergulhar num tempo "estranho", seja ele extático ou imaginário, será jamais extirpado. Enquanto subsistir esse anseio, pode-se dizer que o homem moderno ainda conserva pelo menos alguns resíduos de um comportamento "mitológico". Os traços de tal comportamento mitológico revelam-se igualmente no desejo de reencontrar a intensidade com que se viveu, ou conheceu, uma coisa pela primeira vez; de recuperar o passado longínquo, a época beatífica do "princípio".

Como era de se esperar, é sempre a mesma luta contra o Tempo, a mesma esperança de se libertar do peso do "Tempo morto", do tempo que destrói e que mata. ${ }^{3}$

É importante não perder de vista o caráter em parte nostálgico desse processo poético que, em "A arte como procedimento", Chklóvski chamará de ostranênie. Para Eliade, nosso desejo de mergulhar num tempo estranho tem sua origem na expectativa de recuperar a sensação de estar vivo, de "conhecer ou

2 Ibidem, p. 70.

3 ELIADE, 2013, p. 164-165. 
viver algo pela primeira vez". Assim é também para Chklóvski, o ato de estranhar só tem valor para o crítico na medida em que nos reconduz à experiência original que possuíamos da realidade e suas formas. Nesse sentido, todo estranhamento implica também a ideia de um reencontro - estranha-se para poder ver de novo.

And so, what we call art exists in order to give back the sensation of live, in order to make us feel things, in order to make the stone stony. The goal of art is to create the sensation of seeing, and not merely recognizing, things; the device of art is the "ostranenie" of things and the complication of the form, which increases the duration and complexity of perception, as the process of perception is its own end in art and must be prolonged. Art is the means to live through the making of a thing; what has been made does not matter in art. $^{4}$

Embora a tradução desse ensaio para o inglês esteja mais próxima do original russo, a versão feita para o português revela, no último período do parágrafo, uma modificação que contém já, a meu ver, uma interpretação bastante interessante da teoria de Chklóvski: "A arte é um meio de experimentar o devir do objeto, o que é já 'passado' não importa para a arte". ${ }^{5} \mathrm{O}$ processo de automação transforma o objeto em realidade passada, morta, ainda que estejamos nos referindo ao presente. Quando Eliade afirma que o tempo histórico, cronológico, é o tempo que destrói e que mata, não tem em mente apenas o fato de ser esse o tempo que nos aproxima do término da vida. Importa muito mais o fato de esse ser o tempo que instaura a morte no próprio presente, na própria vida em desenvolvimento, na medida em que favorece o seu desgaste, o seu automatismo - ou seja, a não percepção do seu manifestar-se.

A ação do tempo cronológico confere à repetição um caráter tedioso, promove o esmaecimento da vida em função da sua monotonia. Por outro lado, no tempo mítico, o tempo do "eterno retorno", não existe tédio, porque nele também não existe desgaste. A experiência é vivida infinitas vezes com a mesma

4 CHKLÓVSKI, Op. cit., p. 80.

5 CHKLÓVSKI, 1976, p. 45. 
intensidade, pois o tempo não age sobre ela. Embora Chklóvski não pondere tão objetivamente quanto Eliade a relação da experiência com a passagem do tempo, essa noção se mostra fundamental para ele, uma vez que, a seu ver, em arte a forma não deve ser vista como algo "já feito" (passado) mas como uma manifestação, um devir cuja percepção é prolongada pelo processo de Estranhamento. Nesse sentido, para Chklóvski, a procura por novas formas literárias significou, antes de mais nada, uma revitalização da experiência humana, e não a busca por novas imagens poéticas ou, mais genericamente, por novas experiências, visto que para ele as experiências, assim como as imagens poéticas, se revelariam no fundo sempre as mesmas. O que se busca, em última instância, é a anulação ou ao menos a relativização do efeito do tempo sobre a expressão poética das formas. Esse o sentido "mítico" (e nalguma medida até "religioso") da literatura, de que Chklóvski mostrou-se plenamente ciente ao chamar seu primeiro ensaio de "A ressureição da palavra".

Também não me parece sem relação com todas estas noções a respeito do poético - mais particularmente do poético como meio de revitalização da experiência - que o último grande romance de Tolstói se chamou Ressureição. Em "A arte como procedimento", Chklóvski cita várias vezes o autor, fazendo dele o mais expressivo exemplo do que compreende como processo de "estranhamento". Mas se Chklóvski acha importante frisar que a arte encontra formas diferentes de desautomatização, não aborda o fato de que formas diferentes (ou mesmo formas semelhantes) podem atender a objetivos inteiramente distintos. Seria estranho, a meu ver, compreender o "estranhamento", como às vezes parece propor Chklóvski, como uma finalidade artística em si mesma, uma vez que em cada autor ele atende a um ou a vários propósitos distintos. O crítico se mostra consciente disso ao afirmar que Tolstói nem sempre se vale desse processo para criticar o que ele desaprova, mas não se detém mais longamente sobre a função do ostranênie na obra do autor. É o que tentarei realizar aqui.

Uma das formas mais típicas de estranhamento em Tolstói consiste, segundo Chklóvski, 
in not calling a thing or event by its name but describing it as if seen for the first time, as if happening for the first time. While doing so, he also avoids calling parts of this thing by their usual appellations; instead, he names corresponding parts of other things. Here is an example. In the article "Ashamed", L. Tolstoy estranges the concept of flogging: "people who have broken the law are denuded, thrown down on the floor, and beaten on their behind with sticks," and a couple of lines later: "lashed across their bare buttocks". ${ }^{6}$

A forma como Tolstói torna estranha a noção de chicotear obviamente não pretende devolver a ela sua "beleza perdida" (como se diz em "A ressureição da palavra", quando o poeta faz estranhar a palavra cujo emprego se banalizou). Pretende, sim, estender para o leitor o período da captação do seu sentido, e com isso torná-la mais visível. Mas a função final, quando o autor torna estranha a noção de chicotear (usando, no lugar do verbo, a descrição do seu significado), é pôr em evidência o que ele próprio considera grotesco nesse castigo e com isso torná-lo repugnante também ao leitor. O autor, dessa forma, oferece-nos uma nova estruturação da realidade, ou melhor, de nosso modo de percebê-la, sem alterar, no entanto, a sua essência.

E da mesma forma como esse processo pode restituir o sentido perdido da palavra, pode também privá-la do seu sentido existente. Quando, por exemplo, em Guerra e Paz Tolstói afirma que "a vitória obtida pelos russos em Borodinó não foi o tipo de vitória determinada por pedaços de pano hasteados em varas", sua intenção ao tornar estranha a ideia de "bandeira" é, na verdade, desvalorizá-la, e para isto ele a priva de uma parte do seu sentido (afinal, não importa qual a definição, uma bandeira sempre é, dado o seu caráter simbólico, algo mais do que um pedaço de pano hasteado numa vara). Tolstói emprega aqui o processo de estranhamento como artifício retórico para corroborar seu argumento de que existem na guerra vitórias a um só tempo mais sutis e mais significativas do que aquelas observáveis pelos parâmetros habituais. Oficialmente, os russos perderam a batalha de Borodinó, mas, para o autor, nela fe-

6 CHKLÓVSKI, 2016, p. 82. 
riram de tal modo a moral do exército francês que é este o verdadeiro momento em que tem início a derrocada de Napoleão.

Já no exemplo mais extenso utilizado por Chklóvski, o do conto Kholstomer, Tolstói torna as coisas estranhas, como diz o crítico, não pela nossa própria percepção, mas pela de um cavalo. A propósito desse conto, vale observar que ele se divide em dois momentos bastante distintos: o primeiro, narrado na primeira pessoa, e o segundo, em que o narrador é o próprio cavalo Kholstomer. Não se trata de uma simples mudança de perspectiva, mas de uma mudança também na própria constituição do protagonista. O Kholstomer do primeiro momento é retratado de forma ainda bastante realista, isto é, dentro dos limites de ação e percepção que seriam (ou que ao menos Tolstói retratou como sendo) próprios de um cavalo. Já o Kholstomer do segundo momento não só é capaz de falar (ainda que apenas com outros cavalos) e de narrar sua história, como também de compreender e analisar, num nível inclusive moral, o funcionamento da sociedade e das instituições humanas. O efeito do estranhamento no segundo momento da narrativa não pode ser atribuído, portanto, apenas ao deslocamento de perspectiva do homem para o animal, porque 0 olhar de Kholstomer é mais do que um olhar animal, e não somente porque ele é capaz de contar sua história. Claro que esse olhar é, em parte, o olhar do próprio Tolstói, que se vale da perspectiva do cavalo para demonstrar a forma não natural e em muitos aspectos irracional como, a seu ver, a sociedade está organizada. Mas não é só isso. Vejamos o exemplo citado por Chklóvski, em que se dá o estranhamento da noção de propriedade - mais especificamente, da noção de "seu" (svoy), que o cavalo afirma ter custado a entender e por fim descreve do seguinte modo:

Os homens não dirigem a vida com fatos, mas com palavras. Não os preocupa tanto a possibilidade de fazer ou deixar de fazer alguma coisa, como a de falar de objetos diferentes mediante palavras convencionais. Essas palavras, que consideram muito importantes, são, sobretudo, meu ou minha, teu ou tua. Aplicam-nas a todas as espécies de coisas e de seres, inclusive à terra, aos seus semelhantes e aos cavalos. 
Além disto, convencionaram que uma pessoa só pode dizer meu a respeito de uma coisa determinada. E aquele que puder aplicar a palavra "meu" a um número maior de coisas, segundo a convenção feita, considera-se a pessoa mais feliz. Não sei por que as coisas são desse modo, mas sei que são assim. Durante muito tempo procurei compreender isso, supondo que daí viria algum proveito direto; mas verifiquei que isso não era exato.

Muitas pessoas das que me chamavam seu cavalo nem mesmo me montavam; mas outras o faziam. Não eram elas as que me davam de comer, mas outros estranhos. Também não eram as pessoas que me faziam bem, mas os cocheiros, os veterinários e, em geral, pessoas desconhecidas. Posteriormente, quando ampliei o círculo de minhas observações, convenci-me de que o conceito de meu - e não só com relação a nós, cavalos - não tem qualquer outro fundamento além de um baixo instinto animal, que os homens chamam sentimento ou direito de propriedade. [...]. As pessoas não procuram, em sua vida, fazer o que consideram o bem, e sim a maneira de poder dizer do maior número possível de coisas: é meu. Agora estou persuadido de que nisso reside a diferença essencial entre nós e os homens. Portanto, sem falar de outras prerrogativas nossas, só por este fato podemos dizer, com segurança, que entre os seres vivos, nos encontramos em nível mais alto que o dos homens. A atividade dos homens, pelo menos a dos homens com os quais tenho tratado, se traduz em palavras, ao passo que a nossa se manifesta em fatos. ${ }^{7}$

Creio que seria um erro supor na personagem do cavalo apenas uma máscara para os pontos de vista do próprio Tolstói. Kholstomer é uma construção do autor, e como tal é também parte de uma busca - a busca de Tolstói pelo delineamento de uma certa perspectiva moral. Tão importante quanto a crítica ao conceito de propriedade é a análise do cavalo sobre a linguagem: "a atividade dos homens, pelo menos a dos homens com os quais tenho tratado, se traduz em palavras, ao passo que a nossa se manifesta em fatos". Mas os fatos da vida de Kholstomer, ou seja, seu passado, bem como sua própria crítica à linguagem, não se dão a conhecer senão pelo uso de palavras. Essa ironia consiste, a meu ver, não apenas de uma licença

7 CHKLÓVSKI, 1976, p. 46-47. 
que o autor toma para que o cavalo possa contar sua história. Nela também haveria uma tentativa de conciliar duas formas diferentes de olhar o mundo: a do homem e a do animal. Há, por trás da personagem do cavalo, um olhar humano - isto é, o olhar de um ser que se afastou da natureza, o que nas narrativas de Tolstói geralmente implica uma degeneração -, que busca de algum modo resgatar a sua forma de sentir animal ou natural, sem abdicar, no entanto, da sua consciência.

No plano psicológico, é graças à linguagem que para o homem se institui a noção e a própria percepção de tempo, o tempo cronológico, "que destrói e que mata", como disse Eliade. Há uma afinidade na forma como Tolstói representou a animalidade inerente ao homem com algumas teorias de Nietzsche, que, de acordo com Jeanne Marie Gagnebing, não constrói, em oposição à tradição metafísica clássica, "uma antropologia a partir do ser humano enquanto ser da linguagem, mas a partir do ser animal do homem". Diz ela:

É com uma descrição do animal em geral (das Thiers) que se inicia a reflexão genealógica sobre a ciência histórica [...] e sobre as instituições de direito [...]. Esse animal genérico, que não sabe falar, não sabe senão viver no presente. $\mathrm{A}$ ausência da linguagem é também a condição de uma felicidade que não pode saber de si por si mesma. Quando o animal específico "homem" aprende a falar, essa serenidade se esvai: a linguagem entrega o homem à consciência de sua temporalidade, isto é, à consciência de sua transitoriedade e de sua finitude. "Ela [a criança] apreende a compreender a palavra 'isso era', fórmula que entrega o homem aos combates, ao sofrimento e à náusea, e lhe recorda que sua existência, no fundo, não é nada mais do que um eterno imperfeito", declara Nietzsche que joga com a ambiguidade do termo "imperfeito" (Imperfektum): falta de perfeição e tempo verbal do passado. ${ }^{8}$

A linguagem torna o homem consciente de que o tempo existe e de que ele está fadado a morrer. Mas não é só isso: ela possui o poder de instaurar a morte no próprio presente, na medida em que petrifica sua dinâmica natural, espontânea, pela instituição de uma série de convenções. É o caso do direi-

8 GAGNEBING, 2006, p. 189-190. 
to de propriedade, como o vemos em Kholstomer, que não seria possível sem o estabelecimento de uma série de contratos, os quais por sua vez dependem do uso da memória e da palavra. Algo só pertence a alguém porque em algum momento se convencionou dizer que é assim. A linguagem projeta o passado sobre o presente, substitui os fatos pelas palavras, o "devir" pelo "já feito" e destrói a maleabilidade da vida. Essa é a visão do herói do conto. Não uma visão que busca descobrir a realidade tal como ela é, mas uma que deforma nossa percepção habitual da realidade e nos faz perceber que essa percepção não é de modo algum natural, e sim convencionada.

É importante compreender que, embora o cavalo Kholstomer se considere, como animal, num nível superior ao dos homens, Tolstói não prega qualquer retorno do homem a um estado anterior à noção de propriedade, à linguagem ou à civilização. 0 autor não pretende que voltemos a viver como animais e tampouco lamenta a impossibilidade desse retorno. O seu Kholstomer não é só uma perspectiva, um artifício retórico para o autor promover sua crítica à sociedade. Ele é um herói a quem em determinado momento é concedida a fala pois ele mesmo precisa contar sua história. No começo do conto, como já dissemos, Kholstomer não fala, é um cavalo como qualquer outro, mesmo com suas peculiaridades. Ele faz parte ainda daquele ingênuo mundo inconsciente e atemporal, cujos integrantes não sabem viver senão no presente, como concebeu Nietzsche. Nesse mundo, ele, um velho castrado de pelo malhado, é uma espécie de pária entre os seus companheiros de estábulo, todos cavalos fortes, jovens e pertencentes à mesma boa estirpe. Todos bulem com ele, e quando um dia as provocações se transformam em violência, Kholstomer finalmente pede a palavra. Os outros param para escutá-lo, e ele lhes conta sua história. Mais precisamente, o herói conta a verdade sobre ele: não era o que parecia ser e tampouco fora sempre aquele velho pangaré em que se tornara. Provinha também de linhagem nobre e fora em seu tempo o melhor dos cavalos de corrida. Quando Kholstomer chega ao fim do relato de suas muitas desventuras, já ninguém o vê da mesma forma. É somente pela linguagem e pela memória que o herói recupera e dá a co- 
nhecer aos outros sua "verdadeira" identidade. É em função da linguagem que ele analisa e critica as instituições humanas - e ele as critica, como vemos, não só pelo seu caráter antinatural, mas pelo que ele considera uma imoralidade.

Tolstói não nos deu com Kholstomer simplesmente o mundo visto pela perspectiva de um animal. Deu-nos um personagem em que procuram se harmonizar duas perspectivas distintas: a de uma natureza e a de uma consciência moral. Encontramos com muita frequência, na obra de Tolstói, a descrição de seres totalmente "naturais". No geral são homens, quase sempre jovens, que agem por impulso e conhecem aquela felicidade animal de uma vida toda voltada para o presente, na fácil e ingênua adequação entre o seu desejo e a sua ação; uma vida que não conheceu ainda qualquer relativização profunda, que ainda não se permitiu cercear por quaisquer preceitos morais. É assim que Tolstói descreve a experiência de vários de seus oficiais militares no contexto da guerra (como em Guerra e Paz e Khadji Murát). Trata-se da vida que o próprio autor conheceu, em sua experiência no Cáucaso e na Criméia, e que em muitos de seus textos veio depois a abominar, como um velho cristão que se arrepende dos pecados de sua juventude. Entretanto, ao retratá-la, o autor raramente o fez sem acentuar nela o seu caráter alegre, jovial e espontâneo - como um velho cristão que, se esquecendo momentaneamente de sua conversão, recorda com nostalgia os pecados de sua juventude, do momento anterior à consciência do pecado.

Ler a obra de Tolstói é deparar-se continuamente com a contradição gerada por duas "morais", isto é, dois conjuntos de valores, que coexistem mas jamais se harmonizam: uma moral da razão (muito marcada pelo cristianismo), preocupada em compreender o bem, e outra da natureza, que valoriza sobretudo a força, a intrepidez, a espontaneidade, a vitalidade. Em seu ensaio "Dostoiévski, com moderação", Thomas Mann apontou essa contradição em Tolstói, referindo-se às suas "tentativas imensamente desajeitadas e jamais bem-sucedidas da espiritualização moral de sua corporalidade pagã”. ${ }^{\prime \prime}$. Contudo, embora Mann pareça colocar, numa escala de valor, a "força épica" e 
"o imenso frescor natural" de Tolstói acima de suas tentativas de aperfeiçoamento moral, parece-me impossível pensar o autor sem essa contradição interna, que lhe confere inclusive sua riqueza e complexidade. O próprio Chklóvski compreendeu, em The Energy of Delusion, livro inteiramente dedicado ao autor, essa obra, ao longo de toda a sua trajetória, como a busca pelo delineamento de uma moral própria.

Essa contradição pode ser sentida também em Kholstomer, no próprio exemplo de Chklóvski citado acima. O cavalo de Tolstói possui a noção do bem, dessa abstração da consciência humana, e também a noção de Deus, como se esta constituísse no fundo uma noção natural. O mais inusitado, no entanto, é a condenação que Kholstomer faz do "sentimento ou direito de propriedade", qualificando-o como "um baixo instinto animal". A palavra "animal" (tradução do adjetivo russo jivotnii, também compreensível como "bestial" ou "animalesco") tem aqui um valor negativo. No entanto é um animal - e um animal que considerará, poucas linhas adiante, o ser humano moralmente abaixo dos outros animais - quem a emprega. Além disso, Tolstói se empenha em desmascarar o artificialismo por trás da noção humana de propriedade, e de fato, ao analisá-la, ele a faz soar para nós absolutamente antinatural. Não é também estranho, então, que o autor arremate essa crítica ligando a noção de propriedade justamente às ideias de "instinto" e de "animal"? É preciso considerar que muitas vezes, na obra do autor, a ideia de natureza possui conotações contraditórias. Em A Sonata a Kreutzer, por exemplo, quando deseja condenar o ato sexual, o personagem de Tolstói se refere pejorativamente a ele como uma prática animal; quando, porém, critica a ideia de matrimônio, observa que nenhuma criatura da natureza segue esse hábito, e que, portanto, tampouco o homem o deveria seguir. É como se, para Tolstói, o homem devesse estar, a um só tempo, com a natureza e acima dela, ou como se devesse retornar à natureza mas não se rebaixar a ela. O próprio autor parece não atentar a essa contradição, tamanha a rapidez e facilidade com que ele se desloca de uma perspectiva moral para a outra, como se fosse inconscientemente conduzido por impulsos contrários que se alternam no seu comando. 
Se o considerarmos apenas pelo seu desenvolvimento na história, Kholstomer é um cavalo a quem, em dado momento, é atribuída uma consciência. Mas enquanto criação (e isto me parece o mais importante) Kholstomer é expressão de uma consciência humana que procura resgatar para si certa naturalidade. Não é só o autor descrevendo o mundo pelos olhos de um cavalo, mas o autor acreditando, ao menos nalguns momentos, que, para compreender a vida, é preciso fazê-lo com olhos naturais - os olhos do animal que o homem no fundo ainda é. Pensando ainda naquela contradição fundamental do autor, poderíamos representá-la nos seguintes termos: é preciso voltar à natureza, é preciso voltar a Deus - ao Deus moral do cristianismo. Tolstói buscou muitas vezes (e Kholstomer é um dos exemplos disso) conceber uma visão de mundo em que Deus e a natureza são a mesma coisa, em que voltar a um é necessariamente voltar ao outro. $\mathrm{E}$ há, de fato, muitos pontos de contato entre a sua concepção de Deus e a de natureza, a ponto de ambos parecerem, nalguns momentos, perfeitamente identificáveis. Mas a isto se opõe um problema: Deus, ou ao menos Cristo, é moral, e a natureza, amoral. E embora Tolstói esteja definitivamente comprometido a delinear para si mesmo uma perspectiva moral, não há como deixar em seus escritos uma enorme nostalgia da amoralidade. Se, por exemplo, em Anna Karênina a protagonista é fatalmente ferida pelo sentimento de seu crime de adultério - significando que Anna é, no fundo, uma criatura moral e capaz, portanto, de arrepender-se - seu irmão, Stepan Arkaditch, trai a própria mulher inúmeras vezes com a mais tranquila consciência e é visto por todos como um homem amável. Mais do que isso, o próprio autor não deixa de demonstrar sua simpatia por ele. Trata-se, pois, de um personagem no mais pleno acordo com sua natureza e para quem a moral e o pecado ainda não existem.

Mas se Tolstói jamais parece chegar a um consenso satisfatório quanto àquilo que para ele representa o bem, parece muito mais preciso em demonstrar onde para ele se encontra o mal. O mal, importante notar, nunca (ou ao menos muito raramente) considerado como uma força independente em oposição ao bem, como o consideraram tantos outros autores, 
e sim como o "não bem", como um desvio do bem. Dostoiévs$\mathrm{ki}$, que muitas vezes retratou e pensou o mal como uma força autônoma, inerente ao espírito humano e portanto natural do homem, parece conferir a essa figura maior complexidade. $\mathrm{Ou}$ talvez o correto seja dizer que Tolstói compreendia como mal algo diferente, muito mais específico - e provavelmente, para ele, muito mais danoso. Em sua visão, ou melhor, em seu próprio sistema de valores, o mal é antes de mais nada um desvio da natureza humana, ou da natureza em sentido mais amplo, decorrente sobretudo da civilização.

No percurso da História, o processo civilizatório pode ser compreendido como o estabelecimento de uma série cada vez mais complexa de convenções e instituições. Significa que a civilização é reguladora da vida do homem e em grande parte responsável pela mecanização de sua experiência em sociedade. É neste ponto, a meu ver, que a moral de Tolstói (não aquela pregada pelo autor em seus textos mais moralistas, mas a que muitas vezes subjaz ao seu próprio retrato do mundo) mais se aproxima do pensamento de Chklóvski. Em "A ressureição da palavra", o crítico, ao pensar na morte da palavra, pensava no fundo na morte mais ampla da experiência humana, como ficaria claro depois em "A arte como procedimento". Apenas não levou tanto em consideração o sentido moral dessa morte, como Tolstói o fez e como mais tarde fariam ainda, de forma muito mais direta, alguns intelectuais do século $\mathrm{XX}$, como Albert Camus e Hannah Arendt, ao se depararem com as atrocidades cometidas no período das duas grandes guerras e compreenderem o quanto a violência estava ali banalizada, o quanto ela estava em boa parte reduzida a uma burocracia. Este já era na obra de Tolstói um dos pontos principais de sua crítica à civilização.

O que o autor compreende como mal está geralmente ligado a uma incapacidade de perceber ou, como diria Chklóvski, a uma incapacidade de ver. É, nesse sentido, quase uma forma de ignorância. Mesmo a respeito de uma das mais cruéis e mais detestáveis personagens de Tolstói, o tsar Nicolau I de Khadji Murát, não se pode falar propriamente numa maldade essencial. No fundo, trata-se apenas de um homem grossei- 
ro, medíocre demais e, em função disso, inconsciente demais para atentar às suas próprias contradições, à sua absoluta falta de ética. De forma bem semelhante é descrita a atitude de Napoleão em Guerra e Paz. Neste romance Tolstói se empenhou em demonstrar como aquilo que se compreende como intrepidez e sagacidade naqueles que a História se habituou a chamar de "grandes homens" está ligado, muito mais do que a qualquer virtude, à falta de alguma coisa: sobretudo à incapacidade de relativizar o valor de suas próprias ações e de enxergar o outro (as centenas de milhares de soldados que Napoleão enviara à morte no campo de batalha, por exemplo). Já no que tange às "pessoas comuns", ou mais precisamente à sociedade aristocrática a que Tolstói pertencia e de onde ele retirou a maior parte de seus personagens principais, o autor retratou como mal sobretudo as violências e injustiças regulamentadas e naturalizadas dentro dessa sociedade. A bem dizer, não são propriamente as violências e injustiças o que mais revolta o autor, mas a completa apatia daqueles que as praticam, incapazes sequer de percebê-las e de sentirem-se responsáveis por elas.

O título do primeiro artigo de Chklóvski, "A ressureição da palavra", torna ainda mais sugestivo para nós o título do último romance de Tolstói, Ressureição. Nele se trata do renascimento moral e espiritual de suas duas personagens principais: do príncipe Nekhliúdov e da prostituta Máslova. Duas figuras corrompidas. Após estuprar e engravidar Máslova, antiga criada de sua casa e amor de sua adolescência, Nekhliúdov a abandona com algum dinheiro, depois do que ela sofre uma série de desventuras até finalmente chegar à prostituição. Cerca de dez anos mais tarde, ignorando o destino da moça, o príncipe a reencontra como ré num julgamento do qual ele participava como jurado, injustamente acusada de roubo e assassinato. Por uma série de falhas e descuidos no processo de julgamento, Máslova acaba sentenciada aos trabalhos forçados. Reconhecendo-se culpado pelo destino de sua velha amiga e firmemente decidido a resgatá-la e casar-se com ela, tem início para Nekhliúdov (e também para Máslova) sua longa jornada de redenção. 
Mas o objeto da narrativa está longe de ser apenas o destino individual dessas personagens, assim como o significado de seu título parece remeter a algo maior. Uma vez convencido de seu erro, Nekhliúdov desenvolve um olhar profundamente crítico para o funcionamento de sua sociedade, a começar por uma denúncia dos sistemas judiciário e penitenciário (devido às enormes dificuldades que o herói encontra para libertar Máslova, mesmo demonstrada a falta de provas para incriminá-la, e à observação das péssimas condições de vida nas prisões russas). Esse olhar se desenvolve ao longo da narrativa e acaba por abranger a própria noção de propriedade. O herói representa, nesse sentido, a perspectiva que, antes habituada a reconhecer o mundo, como diria Chklóvski, começa finalmente a vê-lo. Nekhliúdov passa a viver em situação de contínuo estranhamento dos processos que antes para ele haviam sido naturais (e que ele, portanto, não via). O mais surpreendente para o herói é que antes ele não só não fora capaz de perceber as violências e injustiças de sua sociedade, como também todas as pessoas à sua volta permanecem igualmente incapazes de percebê-las. Os outros personagens representam esse olhar viciado, altamente automatizado, com que a vida em sociedade espontaneamente contamina seus indivíduos, insensibilizando-os para as injustiças e contradições nela presentes.

É importante notar que no romance Nekhliúdov abusa de Máslova não exatamente por desejo pessoal, mas quase simplesmente porque sente que é o que deveria fazer, uma vez que era o que faziam (ou ao menos lhe pareciam fazer), em situação semelhante, todos os jovens oficiais militares como ele. Não é 0 ato de violência em si mesmo que Tolstói condena, mas o caráter num certo sentido impessoal desse ato. Ninguém do círculo de Nekhliúdov o incriminaria por sua ação, pois ela é vista e legitimada como normal, de maneira que a ninguém se poderia atribuir a culpa pelo destino de Máslova. Do mesmo modo, ninguém se sente culpado pela condenação injusta da moça e de tantos outros presos, e tampouco pelas condições desumanas que estes são obrigados a enfrentar no cárcere e no transporte para os trabalhos forçados. Tolstói compreendeu a fundo as consequências dos processos de legitimação 
e burocratização da violência, que acabava, em última instância, por despersonalizá-la (como afirmaria mais tarde Hannah Arendt, em suas considerações a respeito da banalidade do mal). O fato de Nekhliúdov assumir a responsabilidade por seu crime tem um sentido muito particular dentro do romance e para ele mesmo. Não se trata apenas de um desejo de fazer justiça ou reparar sua falta, mas sobretudo de não abdicar de sua condição de sujeito. Trata-se, em outras palavras, de assumir-se ou mesmo tornar-se autor de seus próprios atos; de não desaparecer (Chklóvski talvez dissesse "morrer") sensivelmente como parte de um mecanismo - a ordem social - em que o indivíduo permite ser privado de qualquer autonomia.

Para Tolstói, essa morte do sujeito tem início com sua dessensibilização, com a automatização da sua forma de estar no mundo e de percebê-lo, no sentido proposto por Chklóvski. Talvez não haja, para o autor de Ressureição, maior decadência moral do que a condição de quem não vê ou não percebe. Isto me parece possível de se observar já no primeiro parágrafo do romance:

Por mais que aquelas centenas de milhares de pessoas amontoadas num espaço pequeno se empenhassem em estropiar a terra sobre a qual se comprimiam, por mais que atravancassem a terra com pedras para que nela nada crescesse, por mais que arrancassem cada capinzinho que conseguisse abrir caminho para brotar, por mais que enfumaçassem o ar com carvão e petróleo, por mais que cortassem as árvores e expulsassem todos os animais e pássaros - a primavera era a primavera, mesmo na cidade. O sol aquecia, a relva crescia, reanimando-se, e reverdejava em toda parte onde não fora arrancada, não só nos gramados dos bulevares, mas também entre as lajes de pedra, e as bétulas, os álamos, as cerejeiras, desdobravam suas folhas viscosas e aromáticas, as tílias estufavam os brotos, que rebentavam; as gralhas, os pardais e os pombos, na alegria da primavera, já preparavam os ninhos e as moscas zumbiam junto às paredes, aquecidas pelo sol. Também estavam alegres plantas, aves, os insetos, as crianças. Mas as pessoas - as pessoas crescidas, adultas - não paravam de enganar e atormentar a si mesmas e umas às outras. Achavam que o sagrado e importante não era aquela manhã de primavera, não era aquela beleza do mundo de Deus, concedida para o bem de todos 
os seres - beleza que predispunha para a paz, a concórdia e o amor -, mas sim que o sagrado e o importante era aquilo que elas mesmas inventaram a fim de dominarem umas às outras. $^{10}$

Mais uma vez o autor se vale de um deslocamento de perspectiva, de uma reestruturação de nossa percepção habitual da realidade, para torná-la estranha. Assim ele nos faz mergulhar, como diria Eliade, num "tempo estranho", determinado por uma lógica e por um ritmo diferentes, que nos permitiriam ver de novo "como pela primeira vez". Claro que essa forma de ver não é (nem poderia ser) de modo algum pura: encontra-se já submetida aos preceitos morais do autor, como facilmente se percebe nos trechos em que ele toca a ideia de Deus. Mas isto absolutamente não aproxima o texto da pobreza de uma pregação ideológica. Porque o essencial não está na forma como o autor percebe o mundo, mas em como ele desautomatiza e desacelera a percepção que temos deles, obrigando-nos a reconfigurá-lo sob uma outra ótica. É interessante observar que quando Tolstói diz que as pessoas não viam a primavera, faz questão de marcar: "as pessoas crescidas, adultas", isto é, não as crianças, que ele colocara ao lado das plantas, aves e insetos. Em outras palavras, dos seres naturais, como o cavalo Kholstomer. O que o autor evoca positivamente na criança e no animal não é a sua inocência, e sim a sua sensibilidade, que revela o mundo na sua qualidade presente, no seu devir, que o revela na forma de uma contínua manifestação poética. É esse olhar natural que Tolstói busca recuperar e é a partir dele que tenta tecer - não sem contradições, como já dissemos - o seu pensamento moral. 


\section{Referências bibliográficas}

CHKLOVSKY, Viktor. "A arte como procedimento", In: Formalistas Russos 2. ed. Porto Alegre: Editora Globo, 1976.

"Art as Device", in: BERLINA, Alexandra. Shklovsky, a reader. New York: Bloomsbury Academic, 2016.

."The Resurrection of the Word", in: BERLINA, 2016.

The art of Delusion. University of Illinois: Dalkey Archive Press, 2007.

ELIADE, Mircea. Mito e realidade. 6. ed. São Paulo: Perspectiva, 2013.

GAGNEBING, Jeanne Marie. "Os prelúdios de Paul Ricoeur", In: Lembrar escrever esquecer. 2 ed. São Paulo: Editora 34, 2006.

MANN, Thomas. "Dostoiévski, com moderação", in: O escritor e sua missão. Rio de Janeiro: Zahar, 2012.

TOLSTÓI, L. N. Contos Completos. São Paulo: Cosac Naify, 2015.

Guerra e Paz. São Paulo: Cosac Naify, 2013.

Ressureição. 2. Ed. São Paulo: Cosac Naify, 2013. 